\title{
Review of Group Work Principles with Adolescents and their Practical Implementation in Education Environment in the Framework of Potentials Perspective. The Contribute of Andrew Malekoff
}

\author{
MSc. Marinela Sota \\ University of Tirana, FSS, \\ Department of Social Work and Social Policies \\ E-mail: marinelasota@yahoo.com
}

\section{Doi:10.5901/jesr.2013.v3n2p185}

\begin{abstract}
This article will focus on riviewing the group work principles with adolescents and their implementation in the framework of potentials perspective in education environments, such as schools, residential settings, penitentiary institutions or probation service, etc. For the purpose of this article education environment is defined as institutional settings where the work include education and treatment of behavioral problems of adolescents. Institutional settings impose to adolescents certain normes and rules, which can raise the reaction of adolescents and their resistance if they don't precieve the leader of the group, the program and the environment as a safe and respectful aspect to him/her.Group work principles with adolescents of Andrew Malekoff (Malekoff 2001,2002) are a good contribute to the work in education environment of many social workers or other profesionals as: teachers, psychologists, education assistants. The combination of perspective of potentionals with group work priciples of Malekoff is a very good framework for any program focused on adolescents emotional or behavior problems in education environments.
\end{abstract}

Key words: group work principles, education environment, potentials perspective.

\section{Introduction}

Institutional settings impose to adolescents certain normes and rules, which can raise the reaction of adolescents and their resistance if they don't percieve the practicionar, the program and the environment as a safe and respectful aspect to him/her.

The combination of perspective of potentionals with group work priciples of Malekoff is a very good framework for any program focused on adolescents problems in education environment.

\section{The group work with adolescents}

The practice of social work is seen as a practice based on the belief that people have something to offer and they have their own potencials to overcome their problems and to help the others. The help for clients to identify their potentials and resources to improve their situation is not a possibility to social workers, but it's an obligation (Weick\&Saleebey,1995). The commitment to the work with children and parents to develop relations with them and make them participate in programs is now accepted as a must and this was the end of traditional paradigm that sees the social worker as an expert and the client as a passive learner. Theoretical perspective of potentials is one of the perspectives where the group work with adolescents is more and more based on.

\section{The research on practice based on potential perspective}

The research shows that the practice based on potentials perspective has been effective in various aspects of social work. The studies on the raising impact of protective factors and on variables based on potentials (strong points/resources) that reduce or eliminate the risks, make in evidence that motivating and supporting environments are a strong point for the children and adolescents facing problems in certain moments of their life. There are many cases of children facing different risk factors and again they don't develop behavior 
problems such as: substance abuse, violence or crime, school abandonance, adolescent pregnancy. Protective factors are the conditions that save children from the negative effects of risks through reducing risks impacts or chainging the way of children response to the risks. There are developed many protocols in evaluation aspect to help the practiciens to evidence and work with potentials in children ad families (Early,2001; Gilgun,1999; Graybeal,2001; Malekoff, 1997).

An other environment found as effective to implement the practice based on potentials perspective is class environment. An important study (Blum,McNeely\&Rinehart,2002) concluded that for the children of age 13-18 years school results it was definitive their belonging situation to the school and their relations in school. Those who were feeling less related to the school were more involved in risk behaviors. One of the findings of this study was that well-managed classes were very important for the children to develop the sennse of belonging to the school. This perspective implemented in the field of youth development is evaluated as effective especially in identifying personal and social resources that facilitate the positive development of young persons (Benson,1997; Eccles\&Gootman,2002).

Search Institute (Scales\&Leffert,1999) developed a theoretical view for the resources that are important for the positive development of children and adolescents. From this research that studied more than 800 studies in the field resulted that theoretically and practically the resources were: external resources and internal resources.

According to this study external resources are divided in 4 groups: support, empowerment, limits and expectations. Examples are: care in neighboured and school climate, safety in home and community, the society view about the young persons as an asset, high expectations.

Internal resources are also divided in 4 groups: commitment to learning process, positive values, life skills, positive identity. Examplesare: high motivation to have good academic results, care for the others, good planning and decision-taking, sense of aim in life.

\section{Group working principles with adolescents according to A. Malekoff are:}

Principle 1 - Organize groups according to needs and desires of adolescents not based on diagnosis or problems. In many cases the group work fails not for reasons as adolescents resistence or parents, but for the reason of not good planning. An example comes from a practicien that says: "The proffesional literature underlines that group work doesn't function with the children with ADHC, but this has resulted not true in my experience." An other example is coming in this aspect from Wright (2002) in his work with imprisoned children, who wanted to learn boxing. Their unice need was boxing, but their group need was to reduce violence. In this case, during the work to learn boxing children learned to respect others, develop positive identity, learn life skill how to control themselves and how to develop patience. The understanding of needs and desires is serving not only for setting group aim and group objectives but even to chooose technics and methods that will be used during the work with adolescents.

Principle 2- Strucure the groups to accept the person as a whole and not only the problem. A group of adolescents is a extraordinary context to understand different levels of children differences, to confronte their impulse to isolate or objectification of non-ordinary and to achieve the empowerment using their potentials. An example that ilustrate this principle is that brought by Malekoff\&Laser (1999) of a children group, age 7-10 years old, whose parents were dead or divorced. The aim of the group was to reduce isolation, explore loss feeling and help the children to learn ways to face these changes. Group practinar told to the children that next week they should bring something important to them and Allie, 9-years old, her father had passes away some months ago said: I know what I wanted to bring but he is dead already." The practinar waited for the group reaction and after the silence, Jimmy, the child that was mostly focused on his games and not involved at all in the group, stopped what he was doing, went as close ans possivble to Allie, without touching her, and said to her: "You can bring a photo of him". After another pause in group, Allie went to her bag and brought a father's photo. The group was in a circle and they all looked at Allie father's photo. The group learned after some weeks that Jimmy percieved himsels as a nonpleasent company to the others. When he was asked about the perception that teachers could have about him, he said: "They all hate me." This is an excellent example showing in the practice the impemenation of principle of an whole acceptance for the child and the role of practicant in a passive method of creating the needed space to the children to show help and support to each-other. 
Parimi 3- Integrate verbal and nonverbal activities in the group. Adolescents groups should integrate verbal and nonverbal activities as they are in an active phase and they can't only sit and talk together. Exept of structured exercises or tasks, practicioners working with adolescents groups should make space to activities coming from staying together and enrich groups's life.

Malekoff (Malekoff 2001,2002) brings an example from a summer school context for children with emotional disturbances. "Ivan was a child who had been in fostercare and their fostercare parents were alcool dependant and he had had a difficult life. He has a problem with his eyes and he was wearing glasses not in good conditions. He was afraid of being stigmatised by other children in summar school as happened before in his life. Children of his group in summar school decided to wear even them glasses or sun glasses and Ivan was helped to have pleasant glasses. That day Ivan enjoyed staying with other children and a good quality of view. Next day, Ivan told to the group the story of his past in a fostercare institution, where the nurses if he would cry or didn't want to sleep they would put strong light directed to his eyes in order to stay with closed eyes. After he told the story he felt better and all the others understood him better.

Principle 4- Decentralize autority and give the controll to the group members. If the practicionar decentralizes his/her autority and allows the member groups to take control, those have possibility to show what they know to do and this a a real empowerment. The example here can be a group- on-the go, groups which are created in schools, etc. The aims of this groups are to improve the academic results of children and to give emotional help where it's needed. The group consists of adolescents with emotional disturbances that are working with school social worker, dance teacher/painting teacher. Jay is a boy who is followd by social worker and dance teacher. He came to the meeting with social worker and he was depresed. He prefered rock groups with sad songs. He said that he won't go to Mery's party because he doesn't know to dance and he will stay outside as he did last year. Social worker asked Jay if he had danced ever before and he asked 'no'. Social worker asked Jerod (the best dancer in the group to help Jay in dancing), Jerod accepted to help, two other girls joined to the group of boys and the empowerment comes from inside the group. Jay went to the party, danced there and felt himself as part of group and school".

Principle 5- Develop alliance with important persons in children's life. Parents with problems, angry or disapointed teachers cant't be enymies of the practicioner but should be considered as his/her collaborator to achieve results and to maintain it.

Example: A poetry club for children was organised in a school for specific education. The practicionar understood that she should contract with class teachers, she should integrate the group aims with academic and behavior aims of class work. She wants to put focus on prosocial values in all school environment. The group consists of 6 children, 1 teacher and 1 assistant teacher. The children are divided in two sub-groups according to the age.

Practicioner explained to the children the concept of "Poetry in movement" and she said that we can'think of poetry only in paper, but we find poetry in verbal communication, music, moves, etc. The group explored their own movements photographied by them as the poetic ones.

Practicioner presented the value of helping each-other. The elder children helped the younger ones and the younger ones encouraged the elders in exchange.

Teachers did the academic aims list for each child in their class. Examples of aims were: understaning a story, listening and enjoying a story, finding the facts and ideas of the story, reading in phrases and pharagraphs, expresing their opinions on story.

The aims of Poetry Club were: poetry club is a weekly group that will learn to work together, to share and enjoy the work, to built trust through self-express of poetry. The aims of Poetry Club are related with academic results, including following teacher instructions participation in class discusions, reading loudly and fluently. Members of Poetry Club will learn to help, applause and appreciate each-other. Poetry Club met every week, 40 minutes, 10 weeks.

One of techniques used was "Supose what..", the technique consisted of a poetry with hidden rows and the children were asked to complete the poetry, a discusion on the poetry theme followed and each contribution was gifted with small presents. Another technique was the "Non-finished sentences", technique that was considered as a "poetry to be build" and the children were finishing the sentences according to their life, 
interests, thoughts.

The ending phase of Poetry Club was a happy end, three last sessions were aimed to have readings by the poetries of group members, poetries that were already published in Journal of Poetry Club.

Principle 6- Keep focus to the individual change and to the system reform. Practicioners should work that group members become active members of community, they should work for the change in the community.

Participation in efforts for a change begining from the problem identification, deep exploration to find solutions and their implementation is for the young persons a learning posibility to understand the world and the problem solution procces.

Principle 7- Understand and respect the development of the group as a key for the change. Every group has its own life, its own personality seen as group culture by practicioners. Those who work with groups should know, accept and allow that the group proceses be a powerful dynamic for change to group members.

Develop of a group mean a way from the beginning to an end. Practitioners or even in a case of a dance teacher understand the importance of a pleasant closure, so for adolescents a party or a excursion or something else out of the structured content of the program would be a good possibility for them and their families to enjoy the results.

\section{Conclusion}

This article aimed to riview the group work principles with adolescents and their implementation in the framework of potentials perspective in education environments, such as schools, residential settings, penitentiary institutions or probation service, etc.

Group work principles with adolescents of Andrew Malekoff are a good contribute to the work in education environment of many social workers or other profesionals as: teachers, psychologists, education assistants. The combination of perspective of potentionals with group work priciples of Malekoff is a very good framework for any program focused on adolescents emotional or behavor problems in education environments.

\section{Bibliography}

Benson, P. (1997). All kids are our kids: What communities must do to raise caring and responsible children and adolescents, San Francisco, CA:Jossey-Bass

Blum,McNeely\&Rinehart,2002. Improving the odds: The untapped power of schools to improve the health of teens. University of Minnesota, Center for Adolescents Health and Development.

Early, T. (2001). Measures for practice with families from a strength perspective. Families in society, 82 (3), 225-232

Eccles, T\&Gootman, J. (2002) Community programs to promote youth development. Washington, DC: National Academy Press.

Gilgun, J. (1999). Caspars: New tools for assesing client risks and strengths. Families in Society, 80 (5), 450-459

Graybeal, C. (2001). Strengths-based social work assesment: Transforming the dominant paradigm. Families in Society, $82(3), 233-242$

Malekoff, A. (2001). The power of group work with kids: A practicioner's reflection on strengths-based practice. Families in Society: The Journal of Contemporary Human Services,82, 243-249

Malekoff\&Laser (1999)

Malekoff, A.( 1997) Group work with adolescents:Principles and Practice. New York:Guilford Press

Scales, P\&Leffert,N. (1999). Development assests: A synthesis of the scientific research on adolescents development. Mineapolis, MN: Search Institute.

Weick, A.\&Saleebey, D. (1995). A postmodern approach to social work practice, Adelphi University School of Social Work, New York.

Wright, W. (2002). Keep it in the ring: A violence prevention boxing program for juvenile offenders, Annual symposium of the Assocation for the Advancement of Social Work with groups, New York. 